\title{
Different native arbuscular mycorrhizal fungi influence the coexistence of two plant species in a highly alkaline anthropogenic sediment
}

\author{
Rui S. Oliveira $\cdot$ Paula M. L. Castro • \\ John C. Dodd · Miroslav Vosátka
}

\begin{abstract}
Different species of arbuscular mycorrhizal fungi (AMF) can produce different amounts of extraradical mycelium (ERM) with differing architectures. They also have different efficiencies in gathering phosphate from the soil. These differences in phosphate uptake and ERM length or architecture may contribute to differential growth responses of plants and this may be an important contributor to plant species coexistence. The effects of the development of the ERM of AMF on the coexistence of two co-occurring plant species were investigated in root-free hyphal chambers in a rhizobox experimental unit. The dominant shrub (Salix atrocinerea Brot.) and herbaceous (Conyza bilbaoana J. Rémy) plant species found in a highly alkaline anthropogenic sediment were studied in symbiosis with four native AMF species (Glomus intraradices BEG163, Glomus mosseae BEG198,
\end{abstract}

R. S. Oliveira · P. M. L. Castro ( $₫)$

Escola Superior de Biotecnologia, Universidade

Católica Portuguesa, Rua Dr. António Bernardino de

Almeida, 4200-072 Porto, Portugal

e-mail: plcastro@esb.ucp.pt

\section{J. C. Dodd}

PlantWorks Limited, 1/19 Innovation Building 1000, Kent Science Park, Sittingbourne, Kent ME9 8HL, United Kingdom

M. Vosátka

Institute of Botany, Academy of Sciences of the Czech Republic, 25243 Pruhonice, Czech Republic
Glomus geosporum BEG199 and Glomus claroideum BEG210) that were the most abundant members of the AMF community found in the sediment. Different AMF species did not influence total plant productivity (sum of the biomass of $C$. bilbaoana and S. atrocinerea), but had a great impact on the individual biomass of each plant species. The AMF species with greater extracted ERM lengths ( $G$. mosseae BEG198, G. claroideum BEG210 and the four mixed AMF) preferentially benefited the plant species with a high mycorrhizal dependency ( $C$. bilbaoana), while the AMF species with the smallest ERM length $(G$. geosporum BEG199) benefited the plant species with a low mycorrhizal dependency ( $S$. atrocinerea). Seed production of $C$. bilbaoana was only observed in plants inoculated with $G$. mosseae BEG198, G. claroideum BEG210 or the mixture of the four AMF. Our results show that AMF play an important role in the reproduction of $C$. bilbaoana coexisting with $S$. atrocinerea in the alkaline sediment and have the potential to stimulate or completely inhibit seed production. The community composition of native AMF and the length of the mycelium they produce spreading from roots into the surrounding soil can be determinant of the coexistence of naturally co-occurring plant species.

Keywords Arbuscular mycorrhizal fungi · Community composition · Extraradical mycelium · Plant diversity $\cdot$ Plant reproduction $\cdot$ Specificity 


\section{Introduction}

How plant species manage to coexist is an important question in community ecology (Barot and Gignoux 2004; Silvertown 2004). Arbuscular mycorrhizal fungi (AMF), from the phylum Glomeromycota, are a group of soil organisms that form symbiotic associations with roots of the majority of terrestrial plant species (Smith and Read 1997). The contribution of AMF to plant species coexistence has often been neglected, but there has been recent evidence that AMF can mediate plant species coexistence (Hart et al. 2003; van der Heijden et al. 2003).

The ability of many plant species to coexist determines plant biodiversity. Plant community diversity (Francis and Read 1994; Grime et al. 1987; Klironomos et al. 2000; van der Heijden et al. 1998b) and the balance of competition between plant species (Hartnett and Wilson 2002; Kytöviita et al. 2003; Marler et al. 1999) are strongly influenced by AMF.

The extraradical mycelium (ERM) of AMF is a key component of the arbuscular mycorrhizal symbiosis linking colonised roots with the soil matrix (Dodd 1994). One of the most important roles of the ERM in plant growth is the uptake and translocation of phosphate from soil to the roots (Dodd et al. 2000). AMF species can produce different amounts of ERM and can have different efficiencies in gathering phosphate (Helgason et al. 2002; Jakobsen et al. 1992; Jansa et al. 2005; Munkvold et al. 2004). Moreover, AMF species can differ with respect to phosphate metabolism in the ERM (Boddington and Dodd 1999) and can show spatial differences in acquiring soil phosphate (Smith et al. 2000). These differences in phosphate uptake and ERM length or architecture may contribute to differential growth responses of plants (Helgason et al. 2002; Jakobsen et al. 1992; Munkvold et al. 2004) and this may be an important contributor to plant species coexistence (van der Heijden et al. 2003). Furthermore, the differential growth response of plants to different AMF can be great when locally adapted plants and fungi are used (Klironomos 2003). It is, therefore, important to understand the effect of different native AMF species with different ERM lengths and architectures on plant species coexistence.
Promoting plant coexistence is necessary in phytorestoration programs aiming to maintain plant diversity. Plant reproduction on sites targeted for phytorestoration is essential for subsequent survival and spread of the plant species in the field. AMF have been shown to positively influence plant reproduction (Dodd et al. 2002; Koide 2000b). AMF colonisation was also associated with an increase in phosphate uptake when AMF colonisation increased plant reproduction (Koide 2000b). Plant reproduction may be more responsive to colonisation by $\mathrm{AMF}$ in habitats where there is a great phosphate deficit (e.g. degraded and anthropogenic sites) (Dodd et al. 2002; Koide and Dickie 2002). Sanders and Koide (1994) demonstrated that, in a plant community, the presence of AMF decreased reproduction of a non-mycotrophic plant species and increased the reproduction of a strongly mycotrophic plant species. Since different AMF species can take up and transfer phosphate to plants with various efficacies, then it is possible that AMF also have a variety of influences on plant reproduction.

Although AMF are present in most terrestrial biomes (Brundrett 1991), it is unlikely that their influence on plant growth and coexistence is identical in all ecosystems. Studies on the influence of AMF in plant coexistence and plant community structure in anthropogenic habitats are scarce (Malcová et al. 1999). Of special interest are sites targeted for phytorestoration schemes, where plant species with different mycorrhizal dependencies are being considered, since it has been suggested by van der Heijden (2002) that a positive relationship exists between the mycorrhizal dependency of a plant species and the degree to which it responds differently to different AMF species. Oliveira et al. (2001, 2005b) reported the occurrence of arbuscular mycorrhizas on plants growing in a highly alkaline anthropogenic sediment in Northern Portugal. The site had a depauperate vegetation cover of limited diversity and the arbuscular mycorrhizal plants accounted for a large percentage of total plant abundance. Phytorestoration practices are being adopted to rehabilitate the site. The biological significance of AMF for plant coexistence may be pronounced in very harsh environments, such as highly alkaline anthropogenic sediments, 
where low phosphate availability and high $\mathrm{pH}$ and salinity are limiting factors for plant survival and growth.

The aim of the present work was to determine the influence of different native AMF species, alone and together, on the coexistence of two naturally co-occurring plant species in a highly alkaline anthropogenic sediment. Conyza bilbaoana (Asteraceae) was the dominant herbaceous plant species on the study site and had a high mycorrhizal dependency and Salix atrocinerea (Salicaceae) was the dominant shrub and had a low mycorrhizal dependency (Oliveira et al. 2001, 2005b; personal communication). These plant species are often found growing in the vicinity of each other on the site. Conyza bilbaoana and $S$. atrocinerea were inoculated in microcosms containing the alkaline sediment with one of four different native AMF species or a mixture of all four. Plant and fungal development and the reproduction of $C$. bilbaoana were evaluated.

\section{Materials and methods}

Anthropogenic sediment, plant and fungal material

Both the plants and AMF studied in this work occur in the same highly alkaline anthropogenic sediment in Northern Portugal (40 46'30" N, $\left.0835^{\prime} 04^{\prime \prime} \mathrm{W}\right)$. The site was a 10 ha sedimentation pond located in the industrial complex of Estarreja into which had been deposited over a 26 year period 300000 tons of solid waste residues from the production of acetylene and polyvinyl chloride. The sediment had an electrical conductivity of $5980 \mu \mathrm{S} \mathrm{cm}^{-1}, 4.12 \%$ total organic C, $0.23 \%$ total $\mathrm{N}, 1.27 \%$ total $\mathrm{Ca}, 664.2 \mathrm{mg} \mathrm{kg}^{-1}$ total $\mathrm{Na}$ and $11 \mathrm{mg} \mathrm{kg}^{-1}$ Olsen's $\mathrm{P}$ (Oliveira et al. 2005a). The $\mathrm{pH}\left(\mathrm{H}_{2} \mathrm{O}\right)$ values of the sediment were found to be very high (11.8 and 12.6 at depths of $5 \mathrm{~cm}$ and $15 \mathrm{~cm}$, respectively).

The two studied native plant species were Salix atrocinerea Brot. and Conyza bilbaoana J. Rémy, the dominant shrub and herbaceous plant species, respectively, at the study site (Oliveira et al. 2001, 2005b). Seeds of C. bilbaoana and cuttings of $S$. atrocinerea were collected on the study site in order to obtain plants of local provenance and which were adapted to the alkaline sediment.

The four AMF used in this study were Glomus intraradices BEG163, Glomus mosseae BEG198, Glomus geosporum BEG199 and Glomus claroideum BEG210. These species of AMF were isolated as pure cultures derived from trap cultures established with field-collected roots and alkaline sediment (Oliveira et al. 2005b) and represent the majority of the species found at the site (Oliveira et al. 2005b). For a period of 12 months prior to the beginning of the experiment each species of AMF was grown separately in multispore pot culture with both Zea mays L. and Trifolium pratense L. as host plants in a 1:2 $(\mathrm{v} / \mathrm{v})$ mixture of zeolite (clinoptilolite $1.0-2.5 \mathrm{~mm}$, Chemko, SK) and sterilised alkaline sediment from the site (autoclaved twice at $121^{\circ} \mathrm{C}$ for 25 min on two consecutive days). All AMF were propagated at the same time under the same greenhouse conditions.

Experimental design and set-up

Seeds of $C$. bilbaoana were surface sterilised with $0.5 \%(\mathrm{v} / \mathrm{v}) \mathrm{NaOCl}$ for $5 \mathrm{~min}$ and pre-germinated in plastic trays containing a mixture of fine sand and attapulgite clay (Agsorb 8/16, Oil-Dry Ltd., Wisbech, UK) (1:1) pre-autoclaved twice $\left(121^{\circ} \mathrm{C}\right.$ for $25 \mathrm{~min}$ ) on two consecutive days. Trays were placed in a controlled greenhouse with $16 \mathrm{~h}$ photoperiod, with supplementary metal halide $400 \mathrm{~W}$ lighting, $600-800 \mu \mathrm{mol} \mathrm{m} \mathrm{m}^{-2} \mathrm{~s}^{-1}$ photosynthetically active radiation. Temperature and relative humidity varied between 15 and $39^{\circ} \mathrm{C}$ and 60 and $85 \%$, respectively. All cuttings of S. atrocinerea were collected from shoots of the same plant in order to maintain genetic homogeneity. They were trimmed to $5 \mathrm{~cm}$ length and cuttings with $9 \mathrm{~mm}$ diameter were selected and washed four times with tap water (in series of 15 cuttings in $500 \mathrm{ml})$, surface sterilised twice with $0.5 \%(\mathrm{v} / \mathrm{v})$ $\mathrm{NaOCl}$ for $25 \mathrm{~min}$ and rinsed three times with sterile deionised water for $10 \mathrm{~min}$. Each cutting was placed individually in a $25 \mathrm{ml}$ glass tube containing $10 \mathrm{ml}$ of sterile deionised water. After 35 days, seedlings of $C$. bilbaoana of a similar size 
and equally developed cuttings of $S$. atrocinerea were transplanted into Perspex rhizoboxes.

The rhizoboxes $(11 \times 10 \times 10.5 \mathrm{~cm})$ were divided into two root compartments (one at each end) $(4.5 \times 10 \times 10.5 \mathrm{~cm})$ and one hyphal compartment $(\mathrm{HC})(2 \times 10 \times 10.5 \mathrm{~cm})$ in the middle. The root compartments were separated from the hyphal compartment by inserts with a hole $(7 \times 6 \mathrm{~cm})$ sealed with a nylon mesh (Silkprogress Ltd., Moravská Chrastová, CZ) with openings of $35 \mu \mathrm{m}$ in diameter. The size of the openings allowed the hyphae of AMF but not the roots to grow from the root compartments to the central hyphal compartment to help obtain root-free samples of the ERM. All compartments of the rhizoboxes were filled with sterilised alkaline sediment (autoclaved twice at $121^{\circ} \mathrm{C}$ for $25 \mathrm{~min}$ on two consecutive days) collected on the site from the uppermost $5 \mathrm{~cm}$ layer and sieved through a $3 \mathrm{~mm}$ mesh. Microbial populations from the original non-sterile sediment were reintroduced to the autoclaved sediment by adding $50 \mathrm{ml}$ of filtrate (Whatman No. 1) to the entire soil volume in all containers of each rhizobox. The filtrate was obtained from $300 \mathrm{~g}$ of sediment shaken for $2 \mathrm{~h}$ in $3 \mathrm{l}$ of sterile deionised water.

One side of the rhizobox was planted with one seedling of $C$. bilbaoana, while the opposite side was planted with one rooted cutting of $S$. atrocinerea. The experiment comprised 6 treatments: (i) non-inoculated controls, (ii) plants inoculated with Glomus intraradices BEG163, (iii) Glomus mosseae BEG198, (iv) Glomus claroideum BEG210, (v) Glomus geosporum BEG199 and (vi) plants inoculated with a mixture of the four AMF. All treatments were replicated five times. Within each treatment, both plant species were inoculated simultaneously with the same AMF species or mixture of species. At transplanting, each rhizobox received $20 \mathrm{~g}$ (10 g in each root compartment) of the corresponding inoculum consisting of colonised root fragments, hyphae and spores in the growth substrate described above, placed $2 \mathrm{~cm}$ below the root systems. Plants inoculated with the mixture of AMF received an inoculum composed of equal parts of the four inocula. Non-inoculated controls received the same inocula mixture autoclaved twice $\left(121^{\circ} \mathrm{C}\right.$ for $25 \mathrm{~min}$ ) on two consecutive days. Twenty $\mathrm{ml}$ of a filtrate of the AMF inocula mixture were added to the entire soil volume in all containers of each rhizobox to eliminate differences in microbial populations introduced with the AMF inocula (Koide and Li 1989). This inocula filtrate was prepared as described above for the sediment. The plants were grown in the same controlled greenhouse described above and watered every 2 days with deionised water. The rhizoboxes with different inoculation treatments were periodically rotated to different bench positions to minimise differences due to their location in the greenhouse.

\section{Plant parameters analyses}

After a growth period of 8 months the root systems were separated from the shoots and washed to remove adhered sediment. A fresh sub-sample $(0.5 \mathrm{~g})$ of roots of $C$. bilbaoana and S. atrocinerea was collected to assess arbuscular mycorrhizal colonisation (described below). The remaining root system was weighed and dried at $70^{\circ} \mathrm{C}$ for $48 \mathrm{~h}$ together with the shoot. The dried root system and shoot were then re-weighed. The dry root mass of the sub-sample was calculated by multiplying its fresh mass by the dry to fresh mass ratio of the root system. The sum of the dry mass of the root sub-sample with the dry mass of the root system and the dry mass of the shoot gave the total dry weight per plant. The number of seed spikes per plant of $C$. bilbaoana was counted before drying the plant material. The coexistence ratio was determined by dividing the biomass of C. bilbaoana by the sum of the biomasses of C. bilbaoana and S. atrocinerea. The mycorrhizal dependency of $C$. bilbaoana and $S$. atrocinerea was calculated according to the equations presented by van der Heijden (2002) encompassing all AMF treatments. Oven-dried leaves of $C$. bilbaoana and $S$. atrocinerea were finely ground and $0.3 \mathrm{~g}$ of material was digested according to Novozamsky et al. (1983). The phosphorus (P) concentration in leaves was determined by colorimetry (Helios Gamma,Unicam, Cambridge, UK) (Walinga et al. 1989). 
Fungal parameters analyses

At harvest, a sub-sample of fresh roots of $C$. bilbaoana and $S$. atrocinerea was cut into $1-\mathrm{cm}$ pieces and stained using a modified Phillips and Hayman (1970) protocol (Oliveira et al. 2005b). Percentage root length colonised (\% RLC) by AMF was assessed for each plant species by using a gridline intersect method (Giovannetti and Mosse 1980) under a stereomicroscope (SZ60, Olympus, Tokyo, Japan). Stained root pieces were mounted on glass slides and examined with a compound microscope (BX60, Olympus, Tokyo, Japan) ( $\times 100-400)$ to assess the abundance of arbuscules in the mycorrhizal root segments (Trouvelot et al. 1986). The arbuscule abundance was expressed as the percentage of the colonised root length occupied by arbuscules. The sediment from the $\mathrm{HC}$ was homogenised after plant growth and the ERM length was evaluated by a modified membrane filtration technique (Jakobsen et al. 1992). The total length of ERM was assessed using the grid-line intersect method under a compound microscope, with an ocular grid at $\times 200$ magnification (Brundrett et al. 1994). The background length of mycelium found in the nonmycorrhizal treatment was subtracted from the values obtained in the mycorrhizal treatments. The result was expressed in $\mathrm{cm}$ of hyphae per $1 \mathrm{~g}$ of air-dried sediment. The viability of the ERM was evaluated by NADH diaphorase activity (Sylvia 1988) in the remaining ERM extracted from the sediment in the HC by wet-sieving. The proportion of ERM length that contained purple precipitate (NADH diaphorase activity) was estimated under a compound microscope at $\times 200$ magnification.

\section{Statistical analysis}

All the data were analysed using one-way analysis of variance (ANOVA). When a significant $F$-value was obtained $(P<0.05)$, treatment means were compared using the Duncan's multiple range test. The data from the fungal parameters were analysed without including the non-inoculated control treatment. Regression analysis between coexistence ratio and ERM length was conducted without including the non-inoculated control treatment. In order to distinguish between the effect of AMF treatment and ERM length on the coexistence ratio, an analysis of covariance (ANCOVA) was performed using ERM length as the covariate. ANCOVA was conducted at a significance level of 0.05 without including the non-inoculated control treatment. All statistical analyses were performed using SPSS 11.0 .0 software package (SPSS Inc., Chicago, IL, USA).

\section{Results}

All plants of $C$. bilbaoana and $S$. atrocinerea in the mycorrhizal treatments were colonised by the native AMF (Table 1). No AMF colonisation was observed in non-inoculated control rhizoboxes. The \% RLC of $C$. bilbaoana was significantly greater in rhizoboxes inoculated with $G$. intraradices BEG163, G. geosporum BEG199 or the mixed inocula compared with the other treatments. There were no significant differences in \% RLC between $S$. atrocinerea plants in the mycorrhizal treatments. Conyza bilbaoana always had high levels of \% RLC (between 71 and 89\%), whereas $S$. atrocinerea supported low levels (4 or $5 \%$ ).

There was a significant variation in arbuscule abundance in the mycorrhizal root segments of C. bilbaoana and $S$. atrocinerea among the different AMF treatments (Table 1). The arbuscule abundance in the mycorrhizal root segments of $C$. bilbaoana was significantly greater in plants inoculated with the mixed inocula, followed by plants inoculated with $G$. intraradices BEG163 and G. claroideum BEG210. The arbuscule abundance in the mycorrhizal root segments of $S$. atrocinerea was significantly greater in plants inoculated with $G$. claroideum BEG210, followed by plants inoculated with $G$. intraradices BEG163 and the mixed inocula.

There were significant differences in the ERM length and NADH diaphorase activity in the hyphal compartment of the rhizoboxes among the different AMF treatments (Table 2). The ERM length associated with the roots of both plant species was significantly greater in rhizoboxes inoculated with G. mosseae BEG198, G. claroideum BEG210 or the mixed inocula. The NADH 
Table 1 Percentage root length colonised (\% RLC) by AMF and arbuscule abundance (percentage of the colonised root length occupied by arbuscules) of Conyza bilbaoana and Salix atrocinerea at harvest

Treatment

Glomus intraradices BEG163

Glomus mosseae BEG198

Glomus claroideum BEG210

Glomus geosporum BEG199

Mix

$F$-value of one-way ANOVA
Conyza bilbaoana

AMF colonisation (\%RLC)

$\begin{array}{ll}82 \pm 3 \mathrm{~b} & 71 \pm 2 \mathrm{c} \\ 75 \pm 2 \mathrm{a} & 11 \pm 1 \mathrm{a} \\ 71 \pm 2 \mathrm{a} & 45 \pm 2 \mathrm{~b} \\ 87 \pm 3 \mathrm{~b} & 14 \pm 2 \mathrm{a} \\ 89 \pm 3 \mathrm{~b} & 89 \pm 2 \mathrm{~d} \\ F_{4,20}=9^{* * *} & F_{4,20}=355^{* * *}\end{array}$

Salix atrocinerea

\begin{tabular}{ll}
\hline $\begin{array}{l}\text { AMF colonisation } \\
(\% \text { RLC })\end{array}$ & $\begin{array}{l}\text { Arbuscules } \\
(\%)\end{array}$ \\
$5 \pm 0.8$ & $53 \pm 3 \mathrm{c}$ \\
$4 \pm 0.4$ & $13 \pm 2 \mathrm{a}$ \\
$5 \pm 0.5$ & $85 \pm 2 \mathrm{~d}$ \\
$4 \pm 0.5$ & $15 \pm 2 \mathrm{a}$ \\
$5 \pm 0.6$ & $44 \pm 2 \mathrm{~b}$ \\
$F_{4,20}=0.8 \mathrm{NS}$ & $F_{4,20}=161^{* * *}$
\end{tabular}

Means of five observations $( \pm 1 \mathrm{SE}$ ) followed by the same letters within each column are not significantly different according to Duncan's multiple range test at the level of $P<0.05$. *** $P<0.001$, NS non-significant effect

diaphorase activity of the ERM was significantly greater in rhizoboxes inoculated with G. mosseae BEG198 or the mixed inocula.

There were no significant differences in total biomass per rhizobox (sum of the biomasses of both plant species) between non-inoculated controls and plants inoculated with AMF (Fig. 1). However, different AMF treatments had significantly different effects on the biomass partitioning between both plant species (Fig. 2a). Glomus intraradices BEG163, G. mosseae BEG198, G. claroideum BEG210 and the mixed inocula significantly increased the total biomass of C. bilbaoana while decreasing the total biomass of $S$. atrocinerea compared with non-inoculated control plants. Glomus geosporum BEG199 significantly increased total biomass of $S$. atrocinerea, but failed to promote the growth of C. bilbaoana.

Table 2 Extraradical mycelium length and NADH diaphorase activity in the hyphal compartment of the rhizoboxes at harvest

\begin{tabular}{|c|c|c|}
\hline Treatment & $\begin{array}{l}\text { ERM } \\
\text { length } \\
\left(\mathrm{cm} \mathrm{g}^{-1}\right)\end{array}$ & $\begin{array}{l}\text { NADH } \\
\text { diaphorase } \\
\text { activity }(\%)\end{array}$ \\
\hline Glomus intraradices BEG163 & $315 \pm 34 \mathrm{a}$ & $38 \pm 4 \mathrm{a}$ \\
\hline Glomus mosseae BEG198 & $542 \pm 148 b$ & $61 \pm 4 \mathrm{~cd}$ \\
\hline Glomus claroideum BEG210 & $558 \pm 75 b$ & $44 \pm 3 \mathrm{ab}$ \\
\hline Glomus geosporum BEG199 & $271 \pm 46 \mathrm{a}$ & $52 \pm 7 \mathrm{bc}$ \\
\hline Mix & $633 \pm 37 b$ & $68 \pm 1 d$ \\
\hline$F$-value of one-way ANOVA & $F_{4,18}=5^{* *}$ & $F_{4,20}=8 * *$ \\
\hline
\end{tabular}

Means of five observations $( \pm 1 \mathrm{SE})$ followed by the same letters within each column are not significantly different according to Duncan's multiple range test at the level of $P<0.05$. ** $P<0.01$
The mycorrhizal dependency of $C$. bilbaoana and $S$. atrocinerea, calculated encompassing all AMF treatments was 56 and $-44 \%$, respectively.

The leaf $\mathrm{P}$ concentrations in both plant species differed significantly among the different AMF treatments (Fig. 2b). Glomus claroideum BEG210 and the mixed inocula significantly increased the leaf P concentrations of C. bilbaoana, but did not significantly influence that of $S$. atrocinerea. Glomus intraradices BEG163, G. mosseae BEG198 and G. geosporum BEG199 significantly increased the leaf $\mathrm{P}$ concentration of both C. bilbaoana and $S$. atrocinerea compared with the respective non-inoculated control plants.

The AMF treatments had significantly different effects on the coexistence ratio between C. bilbaoana and S. atrocinerea (Fig. 3). Conyza

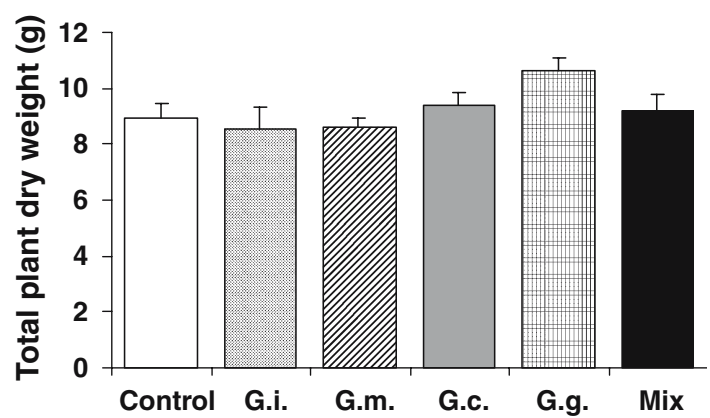

Fig. 1 Total dry weight of both plant species (Conyza bilbaoana and Salix atrocinerea) in each rhizobox, noninoculated, inoculated with Glomus intraradices BEG163 (G.i.), Glomus mosseae BEG198 (G.m.), Glomus claroideum BEG210 (G.c.), Glomus geosporum BEG199 (G.g.) and plants inoculated with a mixture of the four AMF (Mix). Values are means of five observations $\pm 1 \mathrm{SE}$. The $F$-value of one-way ANOVA was $F_{5,24}=2.1(P>0.05)$ 

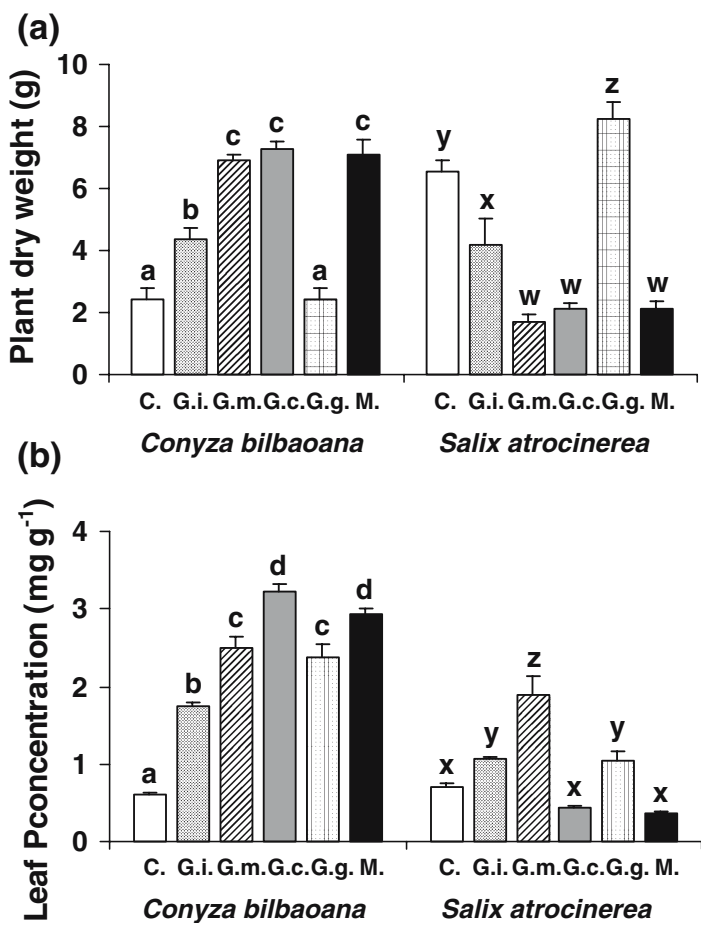

Fig. 2 Total dry weight (a) and leaf phosphorus concentration (b) of Conyza bilbaoana and Salix atrocinerea noninoculated (C.), inoculated with Glomus intraradices BEG163 (G.i.), Glomus mosseae BEG198 (G.m.), Glomus claroideum BEG210 (G.c.), Glomus geosporum BEG199 (G.g.) and plants inoculated with a mixture of the four AMF (Mix). Values are means of five observations \pm 1 SE. The $F$-values of one-way ANOVA for $C$. bilbaoana and $S$. atrocinerea dry weight were $F_{5,24}=46.8(P<0.0001)$ and $F_{5,24}=33.0(P<0.0001)$, respectively. The $F$-values of one-way ANOVA for $C$. bilbaoana and $S$. atrocinerea leaf phosphorus concentration were $F_{5,24}=75.0$ $(P<0.0001)$ and $F_{5,24}=23.5(P<0.0001)$, respectively. Columns marked with different letters within each plant species differed significantly according to Duncan's Multiple Range test at $P<0.05$

bilbaoana had a greater proportional biomass in rhizoboxes inoculated with $G$. intraradices BEG163, G. mosseae BEG198, G. claroideum BEG210 or the mixed inocula, than in noninoculated controls. However, in rhizoboxes inoculated with G. geosporum BEG199 and in non-inoculated controls $S$. atrocinerea had a significantly greater proportional biomass than C. bilbaoana.

Only in the rhizoboxes inoculated with G. mosseae BEG198, G. claroideum BEG210 or the mixed inocula, did C. bilbaoana plants produce seed spikes (Fig. 4). The rhizoboxes with the

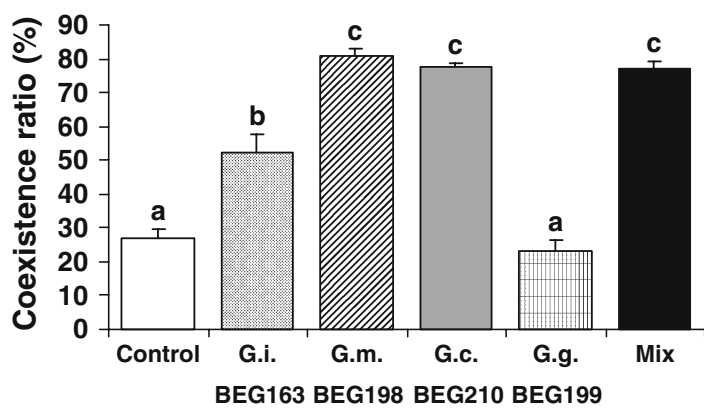

Fig. 3 Coexistence ratio between Conyza bilbaoana and Salix atrocinerea in rhizoboxes non-inoculated, inoculated with Glomus intraradices BEG163 (G.i.), Glomus mosseae BEG198 (G.m.), Glomus claroideum BEG210 (G.c.), Glomus geosporum BEG199 (G.g.) and plants inoculated with a mixture of the four AMF (Mix). The coexistence ratio expresses the biomass of $C$. bilbaoana as a percentage of the total biomass of $C$. bilbaoana and $S$. atrocinerea. Values are means of five observations $\pm 1 \mathrm{SE}$. The $F$-value of one-way ANOVA was $F_{5,24}=74.9 \quad(P<0.0001)$. Columns marked with different letters differed significantly according to Duncan's Multiple Range test at $P<0.05$

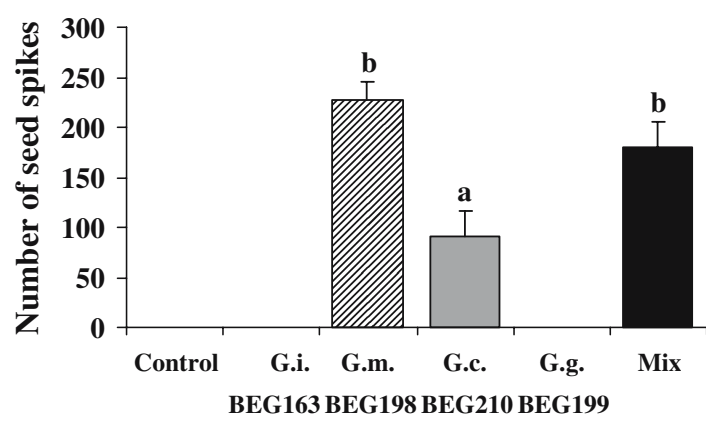

Fig. 4 Number of seed spikes per plant produced by Conyza bilbaoana in rhizoboxes non-inoculated, inoculated with Glomus intraradices BEG163 (G.i.), Glomus mosseae BEG198 (G.m.), Glomus claroideum BEG210 (G.c.), Glomus geosporum BEG199 (G.g.) and plants inoculated with a mixture of the four AMF (Mix). Values are means of five observations $\pm 1 \mathrm{SE}$. The $F$-value of oneway ANOVA was $F_{2,12}=9(P<0.01)$. Columns marked with different letters differed significantly according to Duncan's Multiple Range test at $P<0.05$

most seed spikes produced by $C$. bilbaoana were the ones inoculated with G. mosseae BEG198 or the mixed inocula.

There was a strong significantly positive correlation between the coexistence ratio of both plant species and the ERM length of AMF extracted from the HC (Fig. 5). Species of AMF with high amounts of ERM in the $\mathrm{HC}$ were found 


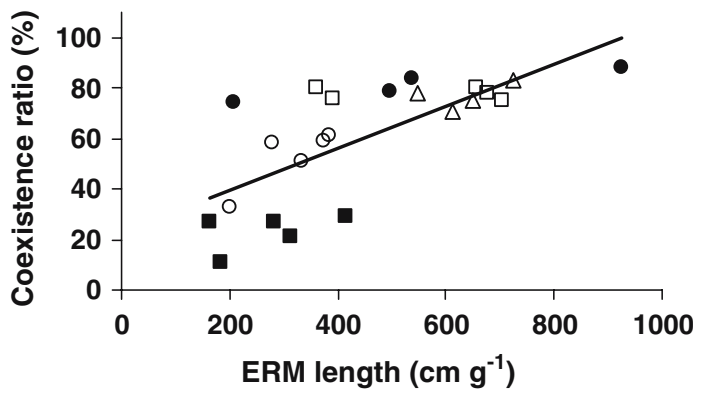

Fig. 5 Relationship between plant coexistence ratio and the extraradical mycelium length in the hyphal compartment of the rhizoboxes, $y=0.083 x+23, R^{2}=0.514$, $P<0.001$. Glomus intraradices BEG163 (open circles), Glomus mosseae BEG198 (closed circles), Glomus claroideum BEG210 (open squares), Glomus geosporum BEG199 (closed squares), mixture of the four AMF (open triangles)

to promote the dominance of $C$. bilbaoana. Conversely, the AMF species with less developed ERM in the HC were found to promote the dominance of $S$. atrocinerea.

The $F$-values of ANCOVA for ERM length and AMF treatment were $F_{1,17}=4.9(P<0.05)$ and $F_{4,17}=30.9(P<0.0001)$, respectively. This shows that after considering the effect of AMF treatment on the coexistence ratio, there is still a significant correlation between the coexistence ratio of both plant species and the ERM length of AMF. The results from ANCOVA also show that the effect of the AMF treatment on the coexistence ratio is significant after accounting for the variation explained by the ERM length.

\section{Discussion}

Different AMF species or the absence of AMF did not influence total plant productivity (sum of the biomasses of both plant species), but had a great impact on the individual biomass of $C$. bilbaoana and $S$. atrocinerea. The coexistence between $C$. bilbaoana and $S$. atrocinerea was changed according to the AMF species present. Similar results were obtained by van der Heijden et al. (2003) in a study with a grass and a forb, where different AMF species influenced how the plants coexisted.

In the present work, the high \% RLC in C. bilbaoana (between 71 and $89 \%$ ) and the low levels in S. atrocinerea (4 or 5\%) were similar to those observed for these plant species growing at the study site (Oliveira et al. 2001; 2005b). Van der Heijden (2001) reported low levels of \% RLC (5\%), but enhanced growth of the plant compared with non-colonised controls in a study with Salix repens cuttings obtained from sand dunes and inoculated with $G$. mosseae in a laboratory microcosm experiment. This shows that even with low levels of \% RLC, species of Salix can greatly benefit from the AMF symbiosis.

Conyza bilbaoana had a high mycorrhizal dependency (56\%) and S. atrocinerea had a low mycorrhizal dependency $(-44 \%)$, calculated using the mean plant dry masses of all AMF treatments. A mycorrhizal dependency $>0$ means that a plant benefits from AMF, while a mycorrhizal dependency $<0$ means that AMF reduces the growth of a plant under the prevailing environmental conditions (van der Heijden 2002). Thus, generally, the growth of $C$. bilbaoana benefited from the mycorrhizal symbiosis, while AMF inhibit the growth of $S$. atrocinerea at this stage of its development. However, if only G. geosporum BEG199 was considered, the mycorrhizal dependency of $C$. bilbaoana and $S$. atrocinerea would have been $0 \%$ and $21 \%$, respectively, indicating that this fungus had a neutral growth effect on the former plant species and a beneficial growth effect on the latter plant species. This shows that the identity of the AMF can determine how plant species coexist and the magnitude of plant growth response can be very high according to the AMF species present, ranging from negative to positive. In our study we used a dominant (frequently found) plant species with a high mycorrhizal dependency ( $C$. bilbaoana) and a subordinate (less frequently found) plant species with a low mycorrhizal dependency ( $S$. atrocinerea) and according to the prediction of the conceptual model proposed by Urcelay and Díaz (2003), the outcome of the presence of AMF should be a decrease in plant species diversity, by enhancing the competitive ability of the dominant and negatively influencing the coexistence of both plant species. For simplification purposes, their model includes only two levels of AMF (absence or presence), however, our results indicate that there can be different effects in plant species 
coexistence (both the dominant or the subordinate plant species can be preferentially favoured) depending on the AMF species present. Therefore, not only absence or presence of AMF, but also the composition of AMF communities must be taken into account in determining the effect of AMF on plant coexistence and diversity (van der Heijden et al. 1998b; 2003). This may be particularly relevant in early succession ecosystems (e.g. anthropogenic sites), with patchy distributions of AMF populations and their host plants, like those studied in the highly alkaline industrial sediment (Oliveira et al. 2005b).

The AMF treatments where higher coexistence ratios were observed (G. mosseae BEG198, G. claroideum BEG210 and the four mixed AMF) were also the ones where greatest ERM lengths were found in the HC. The results show that AMF species with greater ERM lengths away from the rhizosphere preferentially benefited the plant species with a high mycorrhizal dependency (C. bilbaoana), while the AMF species with the lowest ERM length in the HC benefited the plant species with a low mycorrhizal dependency (S. atrocinerea). The observed growth benefit in C. bilbaoana could be attributed to increased phosphate uptake, except in plants inoculated with G. geosporum BEG199. AMF species with greater ERM lengths can have better phosphate uptake efficiencies due to the large surface area of the mycelium used for scavenging the soil (Jakobsen et al. 1992; Leake et al. 2004; Schweiger and Jakobsen, 2000). It is, therefore, possible that the greater ERM lengths of $G$. mosseae BEG198, G. claroideum BEG210 and that resulting from the four mixed AMF may have contributed to the greater proportional biomass of $C$. bilbaoana through an increased phosphate uptake. We obtained no direct relationship between ERM length and viability (evaluated by NADH diaphorase activity). However, the NADH diaphorase activity of the ERM of G. mosseae BEG198, G. claroideum and the four mixed AMF was high, indicating that a large proportion of the hyphae was alive. The reasons for the AMF species with smaller ERM length preferentially benefiting the growth of $S$. atrocinerea are less clear and could not be attributed to the observed plant $\mathrm{P}$ levels. An expansive
ERM may represent a higher drain of photosynthate (Hart and Reader 2002) and it is possible that $S$. atrocinerea was less tolerant to carbon drain than $C$. bilbaoana, especially under reduced light levels (artificial light compared with natural light) (Graham and Eissenstat 1994; 1998). This could, thus, explain the observed growth depression of $S$. atrocinerea inoculated with the AMF species with the greater ERMs (G. mosseae BEG198, G. claroideum BEG210 and the four mixed AMF).

It is possible that $C$. bilbaoana and S. atrocinerea were linked by means of ERM (Simard et al. 2002) spreading from the roots of one plant species, across the hyphal compartment and colonising the roots of the plant species in the opposite compartment; and by means of anastomoses (Giovannetti et al. 2004) between the hyphae of the ERM originating from each of the plant species. These interplant mycorrhizal hyphal connections may have allowed the transfer of plant-derived carbon between the two plants (Fitter et al. 1998; Graves et al. 1997). Van der Heijden (2002) showed that interplant carbon transfer through mycorrhizal hyphal connections is directed towards plant species with the higher mycorrhizal dependencies. Therefore, carbon transfer from $S$. atrocinerea to C. bilbaoana and consequent growth depression of $S$. atrocinerea, could have occurred to a greater extent in the treatments where a larger ERM development was observed. However, the relevance of these interplant carbon transfer mechanisms for plant coexistence is still controversial (Simard et al. 2002), since recent studies have indicated that the transferred carbon was not transported to the shoots of the receiver plant (Fitter et al. 1998) and it likely remained in the intraradical mycelium (Pfeffer et al. 2004) being, therefore, unavailable to the receiver plant.

In the present work, G. geosporum BEG199 produced the smallest ERM away from the rhizosphere when compared with the other species of Glomus studied, even though similar percentages of root colonisation were obtained in the different AMF treatments. Similar observations were reported by Green et al. (1994) in a study with another G. geosporum isolate and two other species of Glomus. The acquisition of phosphate 
requires an extensive ERM developed away from the rhizosphere (beyond the phosphate depletion zone), whereas functions like soil aggregation to roots requires an ERM developed closer to roots (Fitter 2005). Therefore, G. geosporum BEG199 could have improved the growth of $S$. atrocinerea through an effect related to its pattern of ERM development (Dodd et al. 2000). Apart from phosphate acquisition, AMF have several other beneficial effects on plants, such as improved water relations by binding roots to soil (Wright and Upadhyaya 1998), increased resistance to soil-borne plant pathogens (Newsham et al. 1995), uptake of other nutrients (Smith and Read 1997), alleviation of stresses caused by high soil salinity and $\mathrm{pH}$ (Oliveira et al. 2005a; Sylvia and Williams 1992), among others, and since some of these effects can be AMF species specific, it is possible that G. geosporum BEG199 has improved preferentially the growth of $S$. atrocinerea in the highly alkaline sediment, indirectly through some of these effects.

Our experiment was conducted with only one genotype of $S$. atrocinerea and similar studies on the effects of AMF on growth of this plant species and its coexistence with $C$. bilbaoana using different genotypes would help to broaden the conclusions taken in this study.

Variation in ERM length of AMF accounted for a large proportion $(51.4 \%)$ of the variation in the coexistence ratio between $C$. bilbaoana and $S$. atrocinerea, indicating that the length of the ERM of AMF can influence how these two plant species can coexist in a highly alkaline anthropogenic sediment under the experimental conditions employed in this study.

Despite the importance of AMF to plant coexistence (Hart et al. 2003, van der Heijden et al. 2003) little is known about the effect of AMF colonisation on the reproduction of coexisting plant species. In our study, C. bilbaoana without AMF or when colonised by G. intraradices BEG163 or G. geosporum BEG199 did not produce seed and therefore could not reproduce. The AMF treatments where $C$. bilbaoana produced seed spikes were among the treatments where a greater plant biomass and $\mathrm{P}$ concentration was observed, indicating that seed production could have been related to an improved phosphate uptake by some AMF species (Helgason et al. 2002; Jakobsen et al. 1992; Jansa et al. 2005; Munkvold et al. 2004). One of the reasons why different species of AMF can differ in the way they provide phosphate to plants might be related to their lifecycle requirements from the symbiosis. AMF may be able to retain phosphate in the mycelium and regulate its transfer to the plant so as to receive sufficient carbon for the formation of spores over a longer period of time (Dodd et al. 2000). In experiments using tropical forage legumes, Boddington and Dodd (1998) compared the development of the mycelium of three species of AMF and the localisation and activity of the vacuolar alkaline phosphatase in their mycelia. They suggested that different AMF species have different mechanisms for the control of $\mathrm{P}$ transfer, within the mycelium, to the host. Our results suggest that AMF may be playing a very important role in the reproduction of C. bilbaoana coexisting with S. atrocinerea in the alkaline sediment and that not only the absence or presence of AMF, but also the species identity has the potential to stimulate or completely inhibit seed production and, therefore, reproduction. Given that the native AMF can prevent or stimulate $C$. bilbaoana to reproduce and given that $C$. bilbaoana is the dominant plant species at the study site, the identity of the AMF present could have a strong influence on the plant community structure (van der Heijden et al. 1998a). However, long-term studies would be necessary to demonstrate this hypothesis unequivocally.

An increase in AMF diversity from one species to four did not increase total plant productivity and therefore it is unlikely that functional complementarity in phosphate uptake among the different AMF species occurred (Hart and Klironomos 2002; Koide 2000a). No significant differences in biomass were observed between $C$. bilbaoana inoculated with the four AMF and inoculated with the most beneficial single AMF species. Similar results were obtained by van der Heijden et al. (1998b) in an experiment simulating European calcareous grassland using eleven plant species. Glomus geosporum BEG199, the most beneficial AMF species for $S$. atrocinerea, was present in the mixed inocula and yet no growth improvement of $S$. atrocinerea was 
observed in the mixed inocula treatment. Competition for $S$. atrocinerea root niche between the AMF species in the mixed inocula could have occurred (Pearson et al. 1993). Glomus geosporum BEG199 was probably outcompeted by the other AMF and this may have contributed to the lack of increase in plant productivity.

This study shows that native AMF species identity can influence the coexistence between two co-occurring plant species in a highly alkaline anthropogenic sediment and that this influence is related with the length of the ERM of AMF. The identity of the native AMF species also showed a strong impact on the reproduction of the dominant plant species. These findings are relevant not only to plant and mycorrhizal ecology in extreme anthropogenic ecosystems, but also for the application of a mycorrhizal fungi based phytorestoration strategy on the highly alkaline sediment, since promoting plant species coexistence will contribute to the re-establishment of sustainable plant ecosystems.

Acknowledgements R.S.O. wishes to thank Fundação para a Ciência e a Tecnologia and Fundo Social Europeu (III Quadro Comunitário de Apoio), Grant SFRH/BD/ 1464/2000 for financial support of his Ph.D. studies. This work was partly funded by the Grant Agency of the Czech Republic, Grant No. 526/04/0996. Members of the Department of Mycorrhizal Symbioses from the Institute of Botany, Academy of Sciences of the Czech Republic are acknowledged for providing help during the experiments.

\section{References}

Barot S, Gignoux J (2004) Mechanisms promoting plant coexistence: can all the proposed processes be reconciled? Oikos 106:185-192

Boddington CL, Dodd JC (1998) A comparison of the development and metabolic activity of mycorrhizas formed by arbuscular mycorrhizal fungi from different genera on two tropical forage legumes. Mycorrhiza 8:149-157

Boddington CL, Dodd JC (1999) Evidence that differences in phosphate metabolism in mycorrhizas formed by species of Glomus and Gigaspora might be related to their life-cycle strategies. New Phytol 142:531-538

Brundrett M (1991) Mycorrhizas in natural ecosystems. Adv Ecol Res 21:171-313

Brundrett M, Melville L, Peterson RL (1994) Practical methods in mycorrhizal research. Mycologue Publications, Waterloo
Dodd JC (1994) Approaches to the study of the extraradical mycelium of arbuscular mycorrhizal fungi. In: Gianinazzi S, Schüepp H (eds) Impact of arbuscular mycorrhizas on sustainable agriculture and natural ecosystems. Birkhäuser, Basel, pp 147-166

Dodd JC, Boddington CL, Rodriguez A, Gonzalez-Chavez C, Mansur I (2000) Mycelium of Arbuscular Mycorrhizal Fungi (AMF) from different genera: Form, function and detection. Plant Soil 226:131-151

Dodd JC, Dougall TA, Clapp JP, Jeffries P (2002) The role of arbuscular mycorrhizal fungi in plant community establishment at Samphire Hoe, Kent, UK - the reclamation platform created during the building of the Channel tunnel between France and the UK. Biodivers Conserv 11:39-58

Fitter AH (2005) Darkness visible: Reflections on underground ecology. J Ecol 93:231-243

Fitter AH, Graves JD, Watkins NK, Robinson D, Scrimgeour C (1998) Carbon transfer between plants and its control in networks of arbuscular mycorrhizas. Funct Ecol 12:406-412

Francis R, Read DJ (1994) The contributions of mycorrhizal fungi to the determination of plant community structure. Plant Soil 159:11-25

Giovannetti M, Mosse B (1980) An evaluation of techniques for measuring vesicular arbuscular mycorrhizal infection in roots. New Phytol 84:489-500

Giovannetti M, Sbrana C, Avio L, Strani P (2004) Patterns of below-ground plant interconnections established by means of arbuscular mycorrhizal networks. New Phytol 164:175-181

Graham JH, Eissenstat DM (1994) Host genotype and the formation and function of VA mycorrhizae. Plant Soil 159:179-185

Graham JH, Eissenstat DM (1998) Field evidence for the carbon cost of citrus mycorrhizas. New Phytol 140:103-110

Graves JD, Watkins NK, Fitter AH, Robinson D, Scrimgeour C (1997) Intraspecific transfer of carbon between plants linked by a common mycorrhizal network. Plant Soil 192:153-159

Green DC, Vilariño A, Newsam R, Jeffries P, Dodd JC (1994) Quantification of mycelial development of arbuscular mycorrhizal fungi using image analysis. Mycorrhiza 5:105-113

Grime JP, Mackey JML, Hillier SH, Read DJ (1987) Floristic diversity in a model system using experimental microcosms. Nature 328:420-422

Hart MM, Klironomos JN (2002) Diversity of arbuscular mycorrhizal fungi and ecosystem functioning. In: van der Heijden MGA, Sanders IR (eds) Mycorrhizal ecology. Springer, Berlin, pp 225-242

Hart MM, Reader RJ (2002) Host plant benefit from association with arbuscular mycorrhizal fungi: Variation due to differences in size of mycelium. Biol Fertil Soils 36:357-366

Hart MM, Reader RJ, Klironomos JN (2003) Plant coexistence mediated by arbuscular mycorrhizal fungi. Trends Ecol Evol 18:418-423 
Hartnett DC, Wilson GWT (2002) The role of mycorrhizas in plant community structure and dynamics: Lessons from grasslands. Plant Soil 244:319-331

Helgason T, Merryweather JW, Denison J, Wilson P, Young JPW, Fitter AH (2002) Selectivity and functional diversity in arbuscular mycorrhizas of co-occurring fungi and plants from a temperate deciduous woodland. J Ecol 90:371-384

Jakobsen I, Abbott LK, Robson AD (1992) External hyphae of vesicular-arbuscular mycorrhizal fungi associated with Trifolium subterraneum L. 1. Spread of hyphae and phosphorus inflow into roots. New Phytol 120:371-380

Jansa J, Mozafar A, Frossard E (2005) Phosphorus acquisition strategies within arbuscular mycorrhizal fungal community of a single field site. Plant Soil 276:163-176

Klironomos JN (2003) Variation in plant response to native and exotic arbuscular mycorrhizal fungi. Ecology 84:2292-2301

Klironomos JN, McCune J, Hart M, Neville J (2000) The influence of arbuscular mycorrhizae on the relationship between plant diversity and productivity. Ecol Lett 3:137-141

Koide RT (2000a) Functional complementarity in the arbuscular mycorrhizal symbiosis. New Phytol 147:233235

Koide RT (2000b) Mycorrhizal symbiosis and plant reproduction. In: Kapulnik Y, Douds DD (eds) Arbuscular mycorrhizas: physiology and function. Kluwer Academic Publishers, Dordrecht, pp 19-46

Koide RT, Dickie IA (2002) Effects of mycorrhizal fungi on plant populations. Plant Soil 244:307-317

Koide RT, Li M (1989) Appropriate controls for vesiculararbuscular mycorrhiza research. New Phytol 111:3544

Kytöviita M -M, Vestberg M, Tuomi J (2003) A test of mutual aid in common mycorrhizal networks: Established vegetation negates benefit in seedlings. Ecology 84:898-906

Leake J, Johnson D, Donnelly D, Muckle G, Boddy L, Read D (2004) Networks of power and influence: The role of mycorrhizal mycelium in controlling plant communities and agroecosystem functioning. Can $\mathbf{J}$ Bot 82:1016-1045

Malcová R, Vosátka M, Albrechtová J (1999) Influence of arbuscular mycorrhizal fungi and simulated acid rain on the growth and coexistence of the grasses Calamagrostis villosa and Deschampsia flexuosa. Plant Soil 207:45-57

Marler MJ, Zabinski CA, Callaway RM (1999) Mycorrhizae indirectly enhance competitive effects of an invasive forb on a native bunchgrass. Ecology 80:1180-1186

Munkvold L, Kjoller R, Vestberg M, Rosendahl S, Jakobsen I (2004) High functional diversity within species of arbuscular mycorrhizal fungi. New Phytol 164:357-364

Newsham KK, Fitter AH, Watkinson AR (1995) Arbuscular mycorrhiza protect an annual grass from root pathogenic fungi in the field. J Ecol 83:991-1000
Novozamsky I, Houba VJG, Van Eck R, Van Vark W (1983) A novel digestion technique for multi-element plant analysis. Commun Soil Sci Plant Anal 14:239248

Oliveira RS, Castro PML, Dodd JC, Vosátka M (2005a) Synergistic effect of Glomus intraradices and Frankia spp. on the growth and stress recovery of Alnus glutinosa in an alkaline anthropogenic sediment. Chemosphere 60:1462-1470

Oliveira RS, Dodd JC, Castro PML (2001) The mycorrhizal status of Phragmites australis in several polluted soils and sediments of an industrialised region of Northern Portugal. Mycorrhiza 10:241-247

Oliveira RS, Vosátka M, Dodd JC, Castro PML (2005b) Studies on the diversity of arbuscular mycorrhizal fungi and the efficacy of two native isolates in a highly alkaline anthropogenic sediment. Mycorrhiza 16:2331

Pearson JN, Abbott LK, Jasper DA (1993) Mediation of competition between two colonizing VA mycorrhizal fungi by the host plant. New Phytol 123:93-98

Pfeffer PE, Douds DD, Bücking H, Schwartz DP, ShacharHill Y (2004) The fungus does not transfer carbon to or between roots in an arbuscular mycorrhizal symbiosis. New Phytol 163:617-627

Phillips JM, Hayman DS (1970) Improved procedures for clearing and staining parasitic and vesicular-arbuscular mycorrhizal fungi for rapid assessment of infection. Trans Br Mycol Soc 55:158-161

Sanders IR, Koide RT (1994) Nutrient acquisition and community structure in co-occuring mycotrophic and non-mycotrophic old-field annuals. Funct Ecol 8:77-84

Schweiger P, Jakobsen I (2000) Laboratory and field methods for measurement of hyphal uptake of nutrients in soil. Plant Soil 226:237-244

Silvertown J (2004) Plant coexistence and the niche. Trends Ecol Evol 19:605-611

Simard SW, Jones MD, Durall DM (2002) Carbon and nutrient fluxes within and between mycorrhizal plants. In: van der Heijden MGA, Sanders IR (eds) Mycorrhizal ecology. Springer, Berlin, pp 243-265

Smith FA, Jakobsen I., Smith SE (2000) Spatial differences in acquisition of soil phosphate between two arbuscular mycorrhizal fungi in symbiosis with Medicago truncatula. New Phytol 147:357-366

Smith SE, Read DJ (1997) Mycorrhizal symbiosis. Academic Press, London

Sylvia DM (1988) Activity of external hyphae of vesiculararbuscular mycorrhizal fungi. Soil Biol Biochem 20:39-43

Sylvia DM, Williams SE (1992) Vesicular-arbuscular mycorrhizae and environmental stresses. In: Bethlenfalvay GJ, Linderman RG (eds) Mycorrhizae in sustainable agriculture. ASA, Madison, pp 101-124

Trouvelot A, Kough JL, Gianinazzi-Pearson V (1986) Mesure du taux de mycorhization VA d'un système radiculaire. Recherche de méthodes d'estimation ayant une signification fonctionnelle. In: GianinazziPearson V, Gianinazzi S (eds) Physiological and genetical aspects of mycorrhizae. INRA Press, Paris, pp 217-221 
Urcelay C, Díaz S (2003) The mycorrhizal dependence of subordinates determines the effect of arbuscular mycorrhizal fungi on plant diversity. Ecol Lett 6:388391

van der Heijden EW (2001) Differential benefits of arbuscular mycorrhizal and ectomycorrhizal infection of Salix repens. Mycorrhiza 10:185-193

van der Heijden MGA (2002) Arbuscular mycorrhizal fungi as a determinant of plant diversity: In search of underlying mechanisms and general principles. In: van der Heijden MGA, Sanders IR (eds) Mycorrhizal ecology. Springer, Berlin, pp 243-265

van der Heijden MGA, Boller T, Wiemken A, Sanders IR 1998a Different arbuscular mycorrhizal fungal species are potential determinants of plant community structure. Ecology 79:2082-2091 van der Heijden MGA, Klironomos JN, Ursic M, Moutoglis P, Streitwolf-Engel R, Boller T, Wiemken A, Sanders IR 1998b Mycorrhizal fungal diversity determines plant biodiversity, ecosystem variability and productivity. Nature 396:69-72

van der Heijden MGA, Wiemken A, Sanders IR (2003) Different arbuscular mycorrhizal fungi alter coexistence and resource distribution between co-occurring plant. New Phytol 157:569-578

Walinga I, Van Vark W, Houba VJG, van der Lee JJ (1989) Plant analysis procedures (soil and plant analysis, Part 7). Syllabus, Wageningen

Wright SF, Upadhyaya AA (1998) Survey of soils for aggregate stability and glomalin, a glycoprotein produced by hyphae of arbuscular mycorrhizal fungi. Plant Soil 198:97-107 